\title{
Papers
}

\section{Prognosis for South Asian and white patients newly admitted to hospital with heart failure in the United Kingdom: historical cohort study}

Hanna M Blackledge, James Newton, Iain B Squire

\author{
Abstract \\ Objectives To compare patterns of admission to \\ hospital and prognosis in white and South Asian \\ patients newly admitted with heart failure, and to \\ evaluate the effect of personal characteristics and \\ comorbidity on outcome. \\ Design Historical cohort study. \\ Setting UK district health authority (population \\ $960000)$. \\ Participants 5789 consecutive patients newly \\ admitted with heart failure. \\ Main outcome measures Population admission rates, \\ incidence rates for first admission with heart failure, \\ survival, and readmission rates. \\ Results When compared with the white population, \\ South Asian patients had significantly higher age \\ adjusted admission rates (rate ratio 3.8 for men and \\ 5.2 for women) and hospital incidence rates (2.2 and \\ 2.9). Among 5789 incident cases of heart failure, \\ South Asian patients were younger and more often \\ male than white patients (70 (SD 0.6) v 78 (SD 0.1) \\ years and 56.5\% (190/336) v 49.3\% (2494/5057)). \\ South Asian patients were also more likely to have \\ previous myocardial infarction $(10.1 \%(\mathrm{n}=34) v 5.5 \%$ \\ $(\mathrm{n}=278))$ or concomitant myocardial infarction \\ $(18.8 \%(\mathrm{n}=63) v 10.7 \%(\mathrm{n}=539))$ or diabetes $(45.8 \%$ \\ $(\mathrm{n}=154) v 16.2 \%(\mathrm{n}=817)$, all $\mathrm{P}<0.001)$. A trend was \\ shown to longer unadjusted survival for both sexes \\ among South Asian patients. After adjustment for \\ covariables, South Asian patients had a significantly \\ lower risk of death (hazard ratio $0.82,95 \%$ confidence \\ interval 0.68 to 0.99 ) and a similar probability of \\ death or readmission $(0.96,0.81$ to 1.09$)$ compared \\ with white patients. \\ Conclusions Population admission rates for heart \\ failure are higher among South Asian patients \\ than white patients in Leicestershire. At first \\ admission South Asian patients were younger and \\ more often had concomitant diabetes or acute \\ ischaemic heart disease than white patients. Despite \\ major differences in personal characteristics and risk \\ factors between white and South Asian patients, \\ outcome was similar, if not better, in South Asian \\ patients.
}

\section{Introduction}

People of South Asian origin (Indian (subcontinent) origin) comprise the largest ethnic minority group in the United Kingdom-4.1\% of the population in 2001. The incidence of coronary heart disease is around 40\% higher among this group than among the indigenous white population. ${ }^{12}$ Moreover, the onset of coronary heart disease has been suggested to be earlier and mortality higher in South Asian patients. ${ }^{2-4}$ Some studies have shown a similar prognosis in South Asian and white patients after myocardial infarction. ${ }^{5}$ A high prevalence of coronary heart disease in South Asian people might be expected to result in a higher prevalence of heart failure, a major sequela of coronary heart disease.

Population studies and clinical trials of heart failure have under-represented ethnic minority groups. ${ }^{6}{ }^{7}$ In a multiracial cohort admitted to hospital in Birmingham in the early 1990s, Indo-Asian patients were younger than white patients and had a higher prevalence of coronary heart disease and hypertension. ${ }^{8}$ In the United States, disease progression, mortality, and response to treatment in heart failure are less favourable for black patients. ${ }^{9}{ }^{10}$ Thus it seems that outcomes from heart failure may differ with ethnicity.

Leicestershire has a population of around one million, with over twice the national average for people of South Asian ethnic origin. We compared population admission rates for heart failure and outcomes after first admission for heart failure in South Asian and white patients.

\section{Methods}

Data on admissions for heart failure were obtained from Leicestershire health information service. These data comprise self reported coding for ethnicity, for which local coverage is thorough. We defined an admission as a recorded episode of inpatient care with a diagnosis of heart failure (code I50; international classification of diseases, 10th revision) in primary or secondary position. Our denominator was from 1991 census data for the local ethnic population. Data were obtained for patients aged 40 or over. Our principal measure was the ratio of standardised admission rates (South Asian patients to white patients) for men and women.
Leicestershire Health Authority Department of Public Health Medicine Hanna M Blackledge public health analyst

University of Leicester Department of Medicine and Therapeutics, Leicester Royal Infirmary, Leicester LE2 4NU

James Newton clinical research fellow Iain B Squire senior lecturer in medicine

Correspondence to: I B Squire is11@le.ac.uk

bmj.com 2003;327:526 
We obtained data on all Leicestershire residents, aged 40 or over, admitted with heart failure for the first time between 1 April 1998 and 31 March 2001. To counter the effect of migration we included only patients resident in Leicestershire for up to five years before the index admission, according to the family health service register. First admissions were defined as those where patients had no previous admission related to heart failure in these five years as a minimum. Ethnicity was that reported in the hospital discharge data. Validation checks of the South Asian cohort and a matched sample of white patients were performed with patient names.

Mortality was identified through the Office for National Statistics, and follow up hospital events were obtained from Leicestershire Health Authority data. Survival was measured from the date of first admission to the date of death, of readmission, or the end of follow up (30 September 2001). The main outcome measures were death from any cause (all cause survival) and all cause survival or emergency readmission for a cardiovascular event (event free survival).

\section{Statistical analysis}

We assessed the baseline characteristics of the cohorts with the $\chi^{2}$ test for difference in independent proportions. ${ }^{11}$ Crude survival was estimated with the Kaplan-Meier method, and Cox proportional hazards modelling was used to investigate the influence of covariates on outcome. The strategy for selection of the multivariate model was as published by Collett, with a $10 \%$ univariate significance level for inclusion of variables. ${ }^{12}$ Potential modifiers of outcome included in the multivariate analysis were age, sex, ethnicity and social deprivation, and hospital comorbidity, such as diabetes, hypertension, renal insufficiency, stroke, and myocardial infarction.

We retrospectively estimated that, given the proportion of $10 \%$ for South Asian people in Leicestershire, an $\alpha$ of 0.05 , a $\beta$ of 0.1 , and a $58 \%$ survival rate at one year, the observed number of deaths $(n=2746)$ in the two principal ethnic groups should be large enough to detect at least a $20 \%$ difference in all cause mortality.

Our proxy measure of social deprivation was from the index of multiple deprivation 2000 at electoral ward level expressed in fifths (lowest fifth being most deprived), matched using the domicile postcode of the patient at admission. As a proxy of general comorbidity, we took the average hospital stay in each of the five years before the index admission. From this same five years we obtained information on conditions associated with heart failure, including acute myocardial infarction (code 410/I21), other coronary heart disease (411-414/I20/I22-I25), other than coronary heart disease (415-429/I26-I52), hypertension (40/I1), heart valve disease $(39 / \mathrm{I} 0)$, diabetes $(250 / \mathrm{E} 10-\mathrm{E} 14)$, stroke (434,436/I60-I64), renal failure (584-586/N17-N19), and atrial fibrillation or flutter (427.3/I48). Statistical analyses were performed with SPSS, version 9.

\section{Results}

Admission and incidence rates

From 1 April 1998 to 31 March 2001, 14797 patients were admitted with heart failure; heart failure was the primary diagnosis in 4838 (32.7\%). Ethnicity could not be established in $1776(12.0 \%)$ patients.

White patients accounted for $90 \%(\mathrm{n}=11547)$ of all admissions and South Asian patients accounted for $8 \%$ (1037); 87\% (3732) and 10\% (435), respectively, with heart failure in the first diagnostic position.

When South Asian patients were compared with white patients of the same sex, the crude annual rates for admission (heart failure in any position) per 10000 population were higher for both South Asian men (161 v 101) and South Asian women (144 v 93). Differences in crude incidence rates (first admission) were less noticeable (56 $v 44$ for men and $43 v 41$ for women). The South Asian population in Leicestershire is significantly younger that its white counterpart. Figure 1 shows that age standardised admission and incidence rates were higher for South Asian patients of both sexes.

\section{Personal characteristics of incident cohort}

Between 1 April 1998 and 31 March 2001, 5789 patients were newly admitted with heart failure; 5057 $(87.4 \%)$ of these were white patients and $336(5.8 \%)$ South Asian patients (table 1). Follow up ranged from 183 to 1279 days, a minimum of six months for those alive at the end of the observation period. Ethnicity was recorded as not given for $347(5.9 \%)$ patients, but personal characteristics suggested this group to be predominantly white.

Patients in the South Asian cohort were on average eight years younger than those in the white cohort. The South Asian cohort also contained a higher proportion of men $(190 ; 56.5 \%)$ than the white cohort (2494; 49.3\%). Less than $10 \%$ (519) of patients were treated within a cardiological setting within seven days before or after the index admission. No difference was found between cohorts in this respect.

\section{Comorbidity}

Acute myocardial infarction, both before and concomitant with the first admission for heart failure, was more prevalent in South Asian than white patients (before,

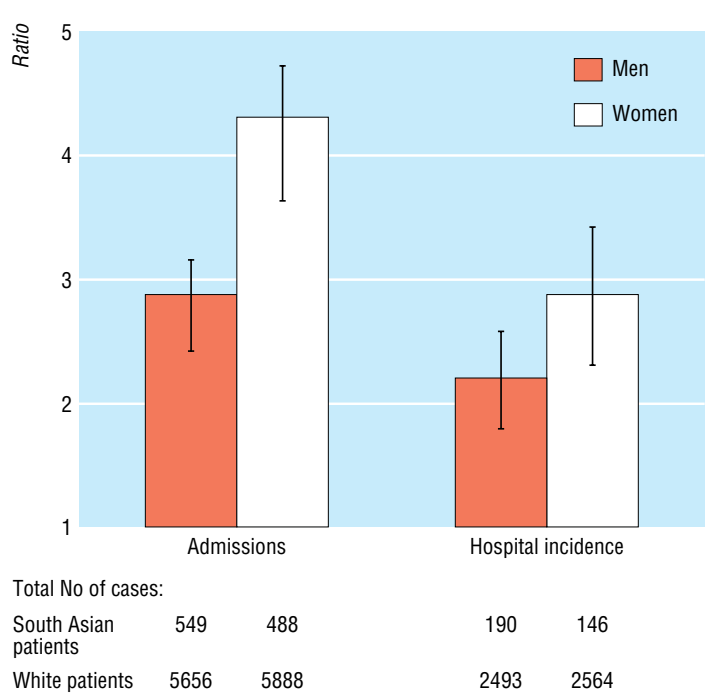

Fig 1 Ratios of age standardised admission (heart failure in any position) and incidence rates of first admission for heart failure for South Asian and white patients (95\% confidence intervals), 1998-2001 
Table 1 Personal and clinical characteristics of 5789 patients with newly diagnosed heart failure. Values are numbers (percentages) of patients unless stated otherwise

\begin{tabular}{|c|c|c|c|c|}
\hline Variable & White patients ( $n=5057$ ) & South Asian patients ( $n=336$ ) & Other $(n=49)$ & Not known $(n=347)$ \\
\hline Mean (SD) age (years); range & $78(9.8) ; 42-107$ & $70(10.4) ; 42-97$ & 75 (11.6); 41-96 & 78 (11.0); $42-99$ \\
\hline Men & $2494(49)$ & $190(57)$ & $23(47)$ & $169(49)$ \\
\hline Women & $2563(51)$ & $146(43)$ & $26(53)$ & $178(51)$ \\
\hline \multicolumn{5}{|l|}{ Deprivation*: } \\
\hline Q1-Q4 & $3114(62)$ & $51(15)$ & $17(35)$ & $218(63)$ \\
\hline Q5 & $1943(38)$ & $285(85)$ & $32(65)$ & $129(37)$ \\
\hline \multicolumn{5}{|l|}{ Comorbidity†: } \\
\hline None & $1501(29.7)$ & $98(29.2)$ & $24(49.0)$ & $227(65.4)$ \\
\hline$<7$ & $2714(53.7)$ & $186(55.4)$ & $23(46.9)$ & $113(32.6)$ \\
\hline $7-29$ & $766(15.1)$ & 49 (14.6) & $2(4.1)$ & $7(2.0)$ \\
\hline$\geq 30$ & $76(1.5)$ & $3(9.0)$ & - & - \\
\hline Median follow up (months) & 11 & 17 & 14 & 4 \\
\hline No of deaths (\% of total) & $2623(51.9)$ & $123(36.6)$ & $18(36.7)$ & $210(60.5)$ \\
\hline
\end{tabular}

${ }^{*}$ Index of multiple deprivation; Q1=least deprived, $05=$ most deprived.

†Length of stay (days) per year, in five years before admission.

Table 2 Patterns of in-hospital comorbidity in five years before or concomitant with diagnosis of heart failure among white and south Asian patients. Values are numbers (percentages) of patients ( $95 \%$ confidence intervals), unless stated otherwise

\begin{tabular}{|c|c|c|c|}
\hline Comorbidity & White patients ( $\mathrm{n}=5057$ ) & South Asian patients ( $n=336$ ) & P value* \\
\hline Acute myocardial infarction: & $769(15.2,14.2$ to 16.2$)$ & $91(27.1,22.4$ to 32.2$)$ & $<0.001$ \\
\hline Before admission with heart failure $\dagger$ & $278(5.5,4.9$ to 6.1$)$ & $34(10.1,6.9$ to 13.3$)$ & $<0.001$ \\
\hline Concomitant with heart failure & $539(10.7,9.8$ to 11.5$)$ & $63(18.8,14.6$ to 22.9$)$ & $<0.001$ \\
\hline Other coronary heart disease & $1264(25.0,23.8$ to 26.2$)$ & $98(29.2,24.4$ to 34.3$)$ & 0.1 \\
\hline Other heart disease§ & $3024(59.8,58.4$ to 61.2$)$ & $147(43.8,38.4$ to 49.2$)$ & $<0.001$ \\
\hline Hypertension & $1484(29.3,28.1$ to 30.6$)$ & $147(43.8,38.4$ to 49.2$)$ & $<0.001$ \\
\hline Valve disease & $250(4.9,4.4$ to 5.6$)$ & $6(1.8,0.7$ to 3.8$)$ & 0.01 \\
\hline Diabetes & $817(16.2,15.2$ to 17.2$)$ & $154(45.8,40.4$ to 51.3$)$ & $<0.001$ \\
\hline Stroke & $393(7.8,7.0$ to 8.5$)$ & $26(7.7,4.9$ to 10.6$)$ & 0.98 \\
\hline Renal failure & $756(14.9,14.0$ to 15.9$)$ & $56(16.7,12.7$ to 20.7$)$ & 0.39 \\
\hline Atrial fibrillation or flutter: & $174(434.5,33.2$ to 35.8$)$ & $46(13.7,10.0$ to 17.4$)$ & $<0.001$ \\
\hline Before admission with heart failure $\dagger$ & $646(12.8,11.9$ to 13.7$)$ & $15(4.5,2.3$ to 6.7$)$ & $<0.001$ \\
\hline Concomitant with heart failure & $148(729.4,28.1$ to 30.7$)$ & $37(11.0,7.7$ to 14.4$)$ & $<0.001$ \\
\hline
\end{tabular}

*Derived with $\chi^{2}$ statistic.

†Diagnosed in hospital at any time within five years before, and excluding, first admission with heart failure.

†No acute myocardial infarction.

$\S N o$ acute myocardial infarction or coronary heart disease.

$10.1 \%$ v $5.5 \%$; concomitant, $18.8 \%$ v 10.7\%). Similarly, diabetes mellitus and hypertension were more commonly recorded among South Asian patients. In contrast, white patients were more likely to have atrial arrhythmias, both before or concomitant with the admission for heart failure (table 2).

\section{Survival}

Over half of all patients $(51.4 \%$; 2974$)$ died before the end of follow up. Two thirds of all mortality (65.5\%; 1948) was due to cardiovascular events. Crude survival analysis gave all cause case fatality rates at 30 days and one year of $21 \%$ and $42 \%$, respectively, for the whole cohort and a median survival of 21 months (95\% confidence interval 20 to 22).

Unadjusted inhospital case fatality rates were lower in South Asian patients than in white patients (13\%v 19\%). Estimates of survival at 30 days, one year, and two years (both to death and to combined event) were consistently higher for South Asian patients (table 3). Univariate Cox regression showed a 38\% lower risk of death and a $17 \%$ lower risk of readmission or death among South Asian patients.

\section{Adjusted survival analysis}

On multivariate analysis the risk of death remained lower (18\%) for South Asian patients whereas the risk of readmission was similar to white patients (table 4 ). Among the factors influencing outcome were age (44\% increase in the risk of death per decade of life) and comorbidity, particularly stroke and renal failure. Adjusted outcomes were better for women. A diagnosis

Table 3 Unadjusted estimates of event free survival for white and South Asian men and women for overall all cause survival and survival to death or readmission for any cause or cardiovascular event. Values are percentages (95\% confidence intervals)

\begin{tabular}{|c|c|c|c|c|}
\hline \multirow[b]{2}{*}{ Survival } & \multicolumn{2}{|c|}{ Men } & \multicolumn{2}{|c|}{ Women } \\
\hline & $\begin{array}{l}\text { White patients } \\
(\mathrm{n}=2494)\end{array}$ & $\begin{array}{c}\text { South Asian } \\
\text { patients }(n=190)\end{array}$ & $\begin{array}{l}\text { White patients } \\
(n=2563)\end{array}$ & $\begin{array}{c}\text { South Asian } \\
\text { patients }(n=146)\end{array}$ \\
\hline \multicolumn{5}{|c|}{ Patients aged $<75$} \\
\hline \multicolumn{5}{|l|}{ Survival: } \\
\hline 30 days & 85 (83 to 87 ) & 85 (76 to 91$)$ & 87 (84 to 90$)$ & 91 (85 to 97 ) \\
\hline 1 year & 70 (67 to 73 ) & 72 (64 to 80 ) & 68 (64 to 72 ) & 79 (71 to 87 ) \\
\hline 2 years & 63 (60 to 66$)$ & 66 (57 to 75$)$ & $59(55 \text { to } 63)^{*}$ & $75(65 \text { to } 85)^{*}$ \\
\hline \multicolumn{5}{|c|}{ Survival to event (death or readmission): } \\
\hline 30 days & 81 (80 to 82 ) & 82 (75 to 89 ) & $84(81$ to 87$)$ & 88 (81 to 95$)$ \\
\hline 1 year & 51 (48 to 54) & 54 (44 to 64$)$ & 51 (47 to 55 ) & 54 (44 to 64$)$ \\
\hline 2 years & 37 (34 to 40 ) & 35 (25 to 45$)$ & 35 (31 to 39 ) & 37 (26 to 48$)$ \\
\hline \multicolumn{5}{|c|}{ Patients aged $\geq 75$} \\
\hline \multicolumn{5}{|l|}{ Survival: } \\
\hline 30 days & 77 (75 to 79 ) & 77 (67 to 87 ) & 78 (76 to 80$)$ & 85 (75 to 95$)$ \\
\hline 1 year & 49 (46 to 52$)$ & 62 (51 to 73 ) & 54 (52 to 56 ) & 62 (48 to 76 ) \\
\hline 2 years & 38 (35 to 41$)$ & 50 (36 to 64$)$ & 43 (40 to 46 ) & 52 (36 to 68$)$ \\
\hline \multicolumn{5}{|c|}{ Survival to event (death or readmission): } \\
\hline 30 days & 74 (72 to 76$)$ & 72 (61 to 83 ) & 77 (75 to 79$)$ & 83 (73 to 93 ) \\
\hline 1 year & 36 (34 to 38 ) & 37 (25 to 49 ) & 41 (39 to 43 ) & 44 (30 to 58 ) \\
\hline 2 years & 22 (20 to 24$)$ & 20 (8 to 32$)$ & 25 (23 to 27$)$ & 30 (16 to 44$)$ \\
\hline
\end{tabular}

*Statistically significant difference. 


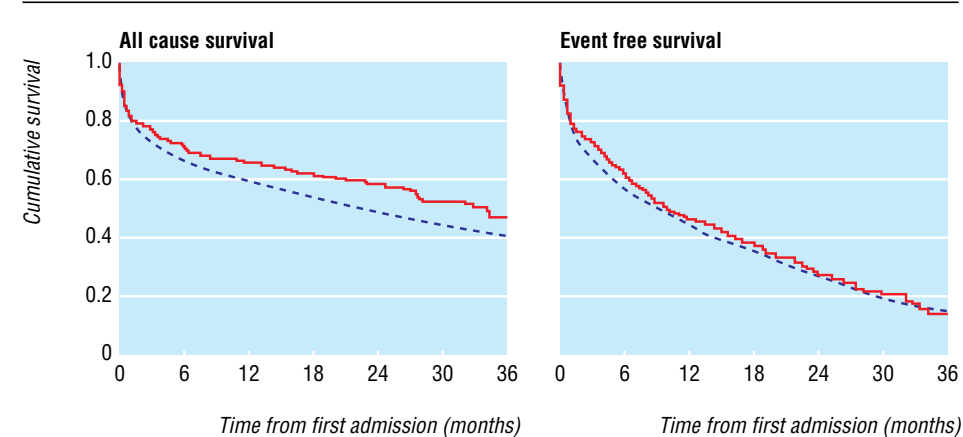

Fig 2 Survival model for South Asian and white patients in cohort of new cases diagnosed with heart failure in hospital between 1 April 1998 and 31 March 2001

of diabetes or concomitant acute myocardial infarction was associated with poorer event free survival. A lower risk was found in patients with hypertension (hazard ratio for death and event free survival 0.77 and 0.88 , respectively) or atrial arrhythmias (0.86 and 0.94). Between 1998 and 2000 the risk of death fell, but the risk of readmission increased. No clear relation was found between deprivation and outcome. Indeed patients living in the most disadvantaged areas (lower fifth) had lower mortality.

\section{Influence of ethnicity}

After correction for covariates, the hazard ratio for all cause mortality was lower in South Asian patients than in white patients and similar for combined events (all cause, $0.82,0.68$ to 0.99 ; combined events, $0.94,0.81$ to 1.09; see table 4). Figure 2 presents the adjusted survival in both groups over the follow up period.

\section{Revascularisation rates}

In the five years before the admission with heart failure, 3.3\% $(\mathrm{n}=11)$ of South Asian patients had undergone a revascularisation procedure compared with $2.1 \%(\mathrm{n}=105)$ of white patients $\left(\chi^{2}=1.6, \mathrm{P}<0.2\right)$. For procedures in the follow up period, values were $6.5 \% \quad(\mathrm{n}=22) \quad$ and $3.1 \% \quad(\mathrm{n}=158)$, respectively $\left(\chi^{2}=10.4, \mathrm{P}=0.001\right)$.

\section{Discussion}

Our report is the first of ethnicity specific outcomes in heart failure from a large UK cohort. South Asian patients admitted for the first time with heart failure were younger and more often had a recorded diagnosis of diabetes or myocardial infarction than white patients. Despite these differences, outcomes were similar for the two groups, and overall mortality was lower for South Asian patients.

Our study has the advantage of a homogeneous South Asian cohort $(94 \%$ of the South Asian population in Leicestershire is of Indian descent), but we cannot assume that our observations apply to other ethnic groups, among whom cardiovascular risk profiles differ. ${ }^{13}$ Similar results were, however, shown in another study, where South Asian people of Pakistani or Bangladeshi descent were in the majority.

Table 4 Results of Cox proportional hazards modelling for all cause and cardiovascular mortality and for unplanned readmissions to hospital. Values are hazard ratios (95\% confidence intervals)

\begin{tabular}{|c|c|c|c|c|}
\hline \multirow[b]{2}{*}{ Variable } & \multicolumn{2}{|c|}{ All cause survival } & \multicolumn{2}{|c|}{ Event free survival ${ }^{\star}$} \\
\hline & Univariate & Multivariate & Univariate & Multivariate \\
\hline Sex (female $v$ male) & $1.01(0.94$ to 1.09$)$ & $0.88(0.82$ to 0.96$)$ & 0.99 (0.93 to 1.06$)$ & 0.92 (0.85 to 0.98$)$ \\
\hline Age (per 10 year increase) & $1.44(1.38$ to 1.50$)$ & $1.42(1.36$ to 1.48$)$ & 1.24 (1.20 to 1.28$)$ & 1.24 (1.20 to 1.28$)$ \\
\hline \multicolumn{5}{|l|}{ Ethnicity: } \\
\hline White & 1.00 & 1.00 & 1.00 & 1.00 \\
\hline South Asian & $0.62(0.51$ to 0.75$)$ & $0.82(0.68$ to 0.99$)$ & $0.83(0.72$ to 0.95$)$ & 0.94 (0.81 to 1.09$)$ \\
\hline Other & $0.69(0.43$ to 1.10$)$ & $0.80(0.50$ to 1.27$)$ & 0.71 (0.47 to 1.04$)$ & 0.78 (0.52 to 1.13$)$ \\
\hline Not known & $1.46(1.27$ to 1.69$)$ & $1.62(1.39$ to 1.87$)$ & $1.02(0.89$ to 1.18$)$ & 1.15 (0.99 to 1.31$)$ \\
\hline \multicolumn{5}{|l|}{ Gross comorbidity: } \\
\hline None & 1.00 & 1.00 & 1.00 & 1.00 \\
\hline$<7$ days & $1.03(0.95$ to 1.12$)$ & $1.07(0.98$ to 1.17$)$ & 1.15 (1.07 to 1.23$)$ & 1.14 (1.06 to 1.22$)$ \\
\hline 7-29 days & 1.60 (1.40 to 1.75$)$ & 1.46 (1.30 to 1.64$)$ & $1.60(1.45$ to 1.76$)$ & 1.44 (1.30 to 1.59$)$ \\
\hline$\geq 30$ days & 1.75 (1.32 to 2.30$)$ & 1.55 (1.17 to 2.05$)$ & 1.77 (1.39 to 2.26$)$ & 1.59 (1.24 to 2.03$)$ \\
\hline \multicolumn{5}{|l|}{ Deprivationt: } \\
\hline Q1 & 1.00 & & 1.00 & 1.00 \\
\hline Q2 & 0.94 (0.81 to 1.08$)$ & $0.96(0.83$ to 1.12$)$ & 0.99 (0.87 to 1.13$)$ & 1.01 (0.89 to 1.15$)$ \\
\hline Q3 & $0.90(0.78$ to 1.04$)$ & $0.94(0.81$ to 1.07$)$ & 1.01 (0.89 to 1.13$)$ & 1.04 (0.92 to 1.17$)$ \\
\hline Q4 & $0.90(0.78$ to 1.02$)$ & 0.95 (0.83 to 1.08$)$ & 0.99 (0.88 to 1.11$)$ & 1.02 (0.91 to 1.15$)$ \\
\hline Q5 & 0.81 (0.71 to 0.91$)$ & $0.88(0.77$ to 0.99$)$ & 0.94 (0.84 to 1.04$)$ & 0.98 (0.88 to 1.08$)$ \\
\hline Diabetes (yes $v$ no) & 0.85 (0.77 to 0.94$)$ & $0.98(0.88$ to 1.09$)$ & $1.06(0.97$ to 1.14$)$ & 1.11 (1.02 to 1.21$)$ \\
\hline $\begin{array}{l}\text { Concomitant acute myocardial } \\
\text { infarction (yes } v \text { no) }\end{array}$ & $0.96(0.85$ to 1.08$)$ & $1.07(0.94$ to 1.17$)$ & $1.04(0.94$ to 1.14$)$ & 1.13 (1.02 to 1.24$)$ \\
\hline Hypertension (yes $v$ no) & $0.76(0.70$ to 0.83$)$ & $0.77(0.71$ to 0.84$)$ & 0.91 (0.85 to 0.97$)$ & 0.88 (0.82 to 0.94$)$ \\
\hline Stroke (yes $v$ no) & $1.57(1.38$ to 1.77$)$ & $1.46(1.28$ to 1.65$)$ & 1.34 (1.22 to 1.53$)$ & 1.26 (1.12 to 1.41$)$ \\
\hline Renal insufficiency (yes $v$ no) & 1.88 (1.70 to 2.06$)$ & 1.85 (1.68 to 2.03$)$ & $1.65(1.51$ to 1.80$)$ & 1.57 (1.44 to 1.72$)$ \\
\hline $\begin{array}{l}\text { Atrial fibrillation or flutter } \\
\text { (yes } v \text { no) }\end{array}$ & $0.93(0.86$ to 1.00$)$ & $0.86(0.79$ to 0.92$)$ & 0.99 (0.92 to 1.06$)$ & 0.94 (0.88 to 1.00$)$ \\
\hline \multicolumn{5}{|l|}{ Year of diagnosis: } \\
\hline $1998-9$ & 1.00 & 1.00 & 1.00 & 1.00 \\
\hline 1999-2000 & 0.89 (0.81 to 0.97$)$ & 0.89 (0.81 to 0.97$)$ & 1.06 (0.98 to 1.15$)$ & 1.06 (0.98 to 1.14$)$ \\
\hline $2000-1$ & 0.89 (0.80 to 0.97$)$ & 0.88 (0.78 to 0.96$)$ & 1.17 (1.07 to 1.27$)$ & 1.14 (1.05 to 1.24$)$ \\
\hline
\end{tabular}

* Survival to death from any cause or emergency readmission for cardiovascular event.

+ Q1=least deprived, $Q 5=$ most deprived. 


\section{Study limitations}

Our study is limited by lack of information on disease severity, non-invasive investigations, and pharmacological treatment before and after admission, all potential modifiers of outcome. We are confident about the robustness of the record linkage system, which allowed identification of all mortality and inhospital events. Although the limitations of hospital discharge data cannot be ignored, such caveats apply equally to both ethnic cohorts and are unlikely to have introduced bias. ${ }^{7}$ In identifying incident cases we included all admissions with heart failure diagnosed in any position. Although this may cause some overestimate, excluding cases with a diagnosis of secondary heart failure may have led to more underestimation.

\section{Admission and incidence rates}

Coronary heart disease, the commonest cause of heart failure, is around $40 \%$ more common in patients from South Asian ethnic minorities in the United Kingdom and other countries compared with indigenous populations. ${ }^{12}{ }^{14}$ Moreover, coronary heart disease has been reported to have earlier onset, to be more extensive, and to have a worse prognosis in South Asian people. ${ }^{2-4}{ }^{15}$ Our data are compatible with a greater prevalence of coronary heart disease in South Asian people, with concomitant or previous myocardial infarction being nearly twice as common than in white patients. The younger age of the South Asian patients also supports earlier onset of disease. As might be expected, age adjusted rates for admission and incidence of heart failure were higher for South Asian patients.

\section{Prognosis of heart failure}

Our study concurs with recently reported annual case fatality rate of $40 \%$ after a first admission for heart failure. ${ }^{16}{ }^{17} \mathrm{~A}$ small proportion of our cohort was treated in a cardiological setting at the time of the index admission. In the context of previous reports from UK centres, indicating similar outcomes in South Asian and white patients after myocardial infarction and after coronary artery surgery, the lower mortality for South Asian patient newly admitted with heart failure is of note. ${ }^{5} 18$ This phenomenon is likely to be multifactorial and could be explained by heart failure being less advanced at the point of first admission, by a differing cause of heart failure in ethnic minority populations, or by better family support after discharge. Better prognosis among South Asian patients remained after adjustment for other prognostic variables and despite higher rates of coronary heart disease and diabetes. The higher prevalence of hypertension and diabetes in South Asian patients perhaps suggests that this cohort may have a higher prevalence of heart failure with preserved left ventricular systolic function. The protective effect of hypertension in our cohort lends some support to this postulate.

Our data are in keeping with the previous observation in heart failure of better outcome with a diagnosis of atrial fibrillation. ${ }^{19}$ Although this arrhythmia was less prevalent for South Asian patients than for white patients, the small numbers of South Asian patients with this comorbidity makes interpretation difficult.

\section{Heart failure in South Asian patients}

In the United States, black patients show more rapid disease progression with heart failure and are readmit- ted more frequently than white patients. ${ }^{90}$ Poorer prognosis for black and Asian patients in the United States after myocardial infarction has been ascribed in part to inequities in access to invasive procedures. ${ }^{21}{ }^{22}$ Our observations do not support such phenomena in South Asian patients in Leicestershire, for whom coronary revascularisation rates were higher than in white patients. There is, however, a parallel to a large study from California where Asian patients (likely to be ethnically different to our South Asian population) had lower rates for admission to hospital, incidence, mortality, and readmission than white patients. ${ }^{23}$

Diabetes and insulin resistance are more prevalent in South Asian patients, and poor glycaemic control may be important in the development of heart failure. ${ }^{19}{ }^{24}{ }^{25}$ In our study a previous hospital diagnosis of diabetes was recorded for over $45 \%$ of South Asian patients, three times the rate in the white cohort. Prospective studies are needed to clarify the importance of diabetes, and its control, in the development and progression of heart failure in ethnic minority populations.

It may be argued that the younger average age of South Asian patients with heart failure simply reflects the age distribution of the local population. However the importance of this observation lies in the fact that the proportion of individuals of an age that puts them at risk of heart failure is increasing disproportionately in the South Asian population. The number of cases of coronary heart disease among this population is predicted to increase markedly by $2008 .^{26}$ Although estimated all cause survival was better for South Asian patients, the combined end point of survival or readmission was similar to white patients. It is likely that the phenomenon of competing risks at least partly explains this observation; survivors have longer in which to experience readmission. Our observations have clear implications for the allocation of healthcare resources in this population.

Better outcome for patients from areas of high deprivation is puzzling. As with all such measures, the index of multiple deprivation is a sum of indicators more relevant to the working age population than to elderly patients, who primarily comprised our cohort. Only two of the six domains in the index-housing and access to services (contributing no more than 20\% of the overall weight)-could feasibly reflect the level of social deprivation among elderly patients. This indicates that the index is a relatively inappropriate measure of deprivation in this type of population. However short of knowing the current income or housing conditions, it is difficult to measure social deprivation in elderly patients.

\section{Conclusions}

Age adjusted admission and incidence rates for heart failure are higher among the South Asian ethnic population of Leicestershire than they are among the white population. Survival data suggest better outcomes for South Asian patients compared with white patients, this on a background of markedly differing risk factor profiles. The observations are clinically important to the UK South Asian population, among whom coronary heart disease and diabetes are common, and in whom the proportion of patients of an age that puts them at risk of heart failure is increas- 


\section{What is already known on this topic}

Coronary heart disease is more prevalent among South Asian people than white people, with an earlier onset and higher mortality

Ethnic minority patients are under-represented in clinical trials

Little is known about the clinical features of heart failure and outcomes in South Asian patients in the United Kingdom

\section{What this study adds}

Admission and incidence rates for heart failure are higher in South Asian patients than in white patients

South Asian patients newly admitted with heart failure are younger (average eight years) and have a history of a higher prevalence of acute myocardial infarction, diabetes, and hypertension than white patients

Even after adjusting for age and in-hospital comorbidity factors, survival is similar, if not better, for South Asian patients

ing. The data indicate that ethnicity is a significant factor in the development and course of the disease. Further studies are required to delineate the cause, clinical course, and prognosis of heart failure in different communities worldwide.

Funding: JN is supported by the Nuffield Hospital, Leicester. The guarantor accepts full responsibility for the conduct of the study, had access to the data, and controlled the decision to publish.

Contributors: All authors contributed to the writing of each draft of the manuscript. IBS will act as guarantor for the paper IBS conceived and designed the study and contributed to data interpretation. JN contributed to data interpretation. HMB extracted and analysed data and contributed to data interpretation.

Competing interests: None declared.

1 Lee J, Heng D, Chia KS, Chew SK, Tan BY, Hughes K. Risk factors and incident coronary heart disease in Chinese, Malays and Asian Indian males; the Singapore cardiovascular cohort study. Int I Epidemiol 2001;30:983-8
2 Balarajan R. Ethnicity and variations in mortality from coronary heart disease. Health Trends 1996,28:45-51.

3 Balarajan R. Ethnic differences in mortality from ischaemic heart disease and cerebrovascular disease in England and Wales. BMJ 1991;302:560-4 Wild S, McKeigue P. Cross sectional analysis of mortality by country of birth. BMJ 1997;314:705-10.

5 Muhktar HT, Littler WA. Survival after acute myocardial infarction in Asian and white patients in Birmingham. Br Heart J 1995;73:122-4.

6 Davies MK, Hobbs FDR, Davis RC, Kenkre JE, Roalfe AK, Hare R, et al. Prevalence of left-ventricular systolic dysfunction and heart failure in the echographic heart of England screening study: a population based study. Lancet 2001;358:439-44.

7 Heiat A, Gross CP, Krumholz HM. Representation of the elderly, women and minorities in heart failure clinical trials. Arch Intern Med 2002;162:1682-8.

8 Lip GYH, Zarafis J, Beevers DG. Acute admissions with heart failure to a district general hospital serving a multiracial population. Int J Clin Pract 1997;51:223-7.

9 Dries DL, Exner DV, Gersh BJ, Cooper HA, Carson PE, Domanski MJ. Racial difference in the outcome of left ventricular dysfunction. $N$ Engl $J$ Med 1999;340:609-16.

10 Exner DV, Dries DL, Domanski MJ, Cohn JN. Lesser response to angiotensin-converting-enzyme inhibitor therapy in black as compared with the white patients with left ventricular dysfunction. $N$ Engl J Med 2001;344:1351-7.

11 Armitage P, Berry G. Statistical methods in medical research. 3rd ed. Oxford: Blackwell Scientific, 1998.

12 Collet D. Modelling survival data in medical research. London: Chapman and Hall, 1994

13 McKeigue PM, Marmot MG, Adelstein AM, Hunt SP, Shipley MJ, Butler SM, et al. Diet and risk factors for coronary heart disease in Asians in north-west London. Lancet 1985;2:1086-90.

14 Hughes K, Lun KC, Yeo PPB. Cardiovascular diseases in Chinese, Malay and Indians in Singapore. J Epidemiol Community Health 1990;44:24-8.

5 Lowry PJ, Glover DJ, Mace PJE, Littler WA. Coronary artery disease in Asians in Birmingham. Br Heart J 1984;52:610-3.

16 Stewart S, MacIntyre K, MacLeod MMC, Bailey, AEM, Capewell S, McMurray JJV. Trends in hospitalisation for heart failure in Scotland 1990-1996. Eur Heart J 2001;22:209-17.

17 Jong P, Vowinckel E, Liu P, Gong Y, Tu JV. Prognosis and determinants of survival in patients newly hospitalized for heart failure. Arch Intern Med

18 Goldsmith I, Lip GYH, Tsang G, Patel RL. Comparison of primary coronary artery bypass surgery in British Indo-Asian and white Caucasian population. Eur Heart J 1999;20:1094-1100

19 MacIntyre K, Capewell S, Stewart S, Chalmers JWT, Boyd J, Finlayson J, et al. Evidence of improving prognosis in heart failure. Circulation 2000;102:1126-31.

20 Alexander M, Grumbach K, Selby J, Brown AF, Washington E. Hospitalisation for congestive heart failure; explaining racial differences. JAMA 1995;274:1037-42.

21 Sheifer SE, Escarce JJ, Schulman KA. Race and sex differences in the management of coronary artery disease. Am Heart J 2000;139:848-57.

22 Taira DA, Seto DB, Marciel C. Ethnic disparities in care following acute coronary syndromes among Asian Americans and Pacific Islanders during the initial hospitalization. Cell Mol Biol 2001;47:1209-15.

23 Alexander M, Grumbach K, Remy L, Rowell R, Massie BM. Congestive heart failure hospitalizations and survival in California: patterns according to race/ethnicity. Am Heart J 1999;137:919-27.

24 McKeigue PM, Ferrie JE, Pierpoint T, Marmot MG. Association of early onset coronary heart disease in South Asian men with glucose intolerance and hyperinsulinaemia. Circulation 1993;87:152-61.

25 Iribarren C, Karter AJ, Go AS, Ferrara A, Liu JY, Go AS, et al. Glycaemic control and heart failure among adult patients with diabetes. Circulation 2001;103:2668-73.

26 Lowy AGJ, Woods KL, Botha JL. The effects of demographic shift on coronary heart disease mortality in a large migrant population at high risk J Public Health Med 1991;13:276-80.

(Accepted 9 July 2003) 